\title{
AFECTO E CONFLICTO EN LAS INTERACCIONES EN AMBIENTES VIRTUALES DE APRENDIZAJE
}

\section{(AFFECTION AND CONFLICT IN LEARNING MANAGEMENT SYSTEM INTERACTIONS)}

\author{
Ana Luisa Mülbert \\ Ariane Girondi \\ Alice T. Cybis Pereira \\ Marina Keiko Nakayama \\ Universidade Federal de Santa Catarina, UFSC (Brasil)
}

\section{RESUMO}

A interação em ambientes virtuais de aprendizagem (AVAs) é fenômeno de substancial importância para o sucesso de programas de ensino a distância. Neste artigo discutimos sobre a manifestação de afeto e conflito que permeiam as interações ocorridas em AVAs de um sistema formal de ensino superior. A partir dos diálogos desenvolvidos pelos alunos foram identificados padrões de interação que revelam manifestações de afeto positivas e/ ou de conflito. Os dados coletados correspondem aos diálogos desenvolvidos entre alunos e professores em um curso superior a distância, submetidos à análise de seu conteúdo em uma abordagem interpretativista. A compreensão do afeto, do conflito e da negociação nas relações em ambientes de aprendizagem on line parecem relevantes para a construção de espaços de aprendizagem que potencializem a manifestação do afeto e a superação do conflito.

Palavras-chave: ambiente virtual de aprendizagem, educação a distância, afeto, conflito, negociação.

\begin{abstract}
Interaction in virtual learning environments (VLEs) is a phenomenon of substantial importance for the success of distance learning programs. In this article, we discuss manifestations of emotions and conflict that permeate interactions occurring in VLEs, that is, within a formal system of college education. Beginning our focus on dialogues developed by the students, we identify several patterns of interaction that reveal emotions and/or conflict. The collated data correspond to dialogues developed between students and teachers in a college distance educational system, which were subjected to content analysis using an interpretive approach. The understanding of emotional content, conflict and negotiation in online learning
\end{abstract}


environments is considered to be relevant to the construction of learning spaces that enhance the manifestation of emotions and the overcoming of conflict.

Keywords: virtual learning environment; distance education; emotions, conflict, negotiation.

O rápido crescimento da demanda por conhecimento e atualização, assim como o amadurecimento de tecnologias da informação e da comunicação, tem oportunizado o crescimento significativo da modalidade de educação a distância, frequentemente mediada por Ambientes Virtuais de Aprendizagem (AVAs). Nesta linha desenvolvem-se novos modelos pedagógicos que possibilitam que a educação aconteça muito além dos limites de uma sala de aula convencional, que demandam por novas habilidades na interação e no diálogo entre professor e aluno.

Para compreender melhor o fenômeno da interação que se dá na aprendizagem a distância, este trabalho busca investigar as manifestações de afeto e conflito que ocorrem nas interações por meio de AVAs. Esta investigação se dá pela análise dos diálogos estabelecidos pelos alunos, em um curso superior a distância mediado por AVA, de modo a reconhecer as manifestações explícitas de afeto e conflito e o contexto em que se inserem.

\section{A INTERATIVIDADE EM EDUCAÇÃO A DISTÂNCIA}

A educação a distância (EAD) é o processo de ensino-aprendizagem, mediado por tecnologias, onde professores e alunos estão separados espacial e/ou temporalmente. A estrutura da $\mathrm{EAD}$ modifica o esquema de referência associado à presença do professor e do estudante uma vez que decompõe o ato pedagógico em dois momentos e dois lugares. $\mathrm{O}$ ensino é mediado, a aprendizagem resulta do trabalho do estudante, a reação do aluno face ao conteúdo vem indiretamente ao docente e a interação em sala de aula é em grande parte reduzida (Neder, 1999). A EAD baseia-se em um sistema tecnológico de comunicação bidirecional que substitui a interação pessoal entre professor e aluno em sala de aula. Isso se dá pela ação sistemática e conjunta de diversos recursos didáticos e pelo apoio de uma organização e tutoria que propiciam a aprendizagem independente e flexível dos alunos (García Aretio, 1994).

Segundo Oblinger (2006) os recursos da tecnologia da informação contribuem para redefinir os espaços de aprendizagem. $\mathrm{Na} \mathrm{EAD}$ os espaços físicos são substituídos por espaços virtuais apresentados na forma de ambientes virtuais de aprendizagem, que fornecem ferramentas para mediar o processo educacional. No desenvolvimento das atividades, a interatividade é um fenômeno importante, que precisa ser bem compreendido para que se possa propor práticas pedagógicas 
adequadas e eficientes. Segundo Mattar (2009) em EAD a interatividade é um aspecto complexo, pois os agentes envolvidos interagem de diversas maneiras, por meio de variadas ferramentas e com expectativas e objetivos bem distintos.

A interação que ocorre na EAD deve ser vista como um fenômeno pedagógico e não simplesmente como uma mera questão de distância geográfica. A distância física conduz a um hiato na comunicação, um espaço psicológico de concepções errôneas potenciais entre instrutores e alunos, que precisa ser suplantado por técnicas especiais de ensino. A superação da distância se dá por meio de procedimentos diferenciadores na elaboração da instrução e na facilitação da interação (Moore, 2007).

A distância física entre professor e aluno é tão significativa que chega ao ponto de afetar seus comportamentos e interferir em seus diálogos. Os diálogos escritos tendem a ser mais formais e estruturados do que os diálogos baseados na oralidade. Quando o diálogo se dá por meio de ferramentas on line tende a ser também muito mais frequente e rápido se comparado com outros meios também utilizados em EAD como a correspondência, o áudio e as videoconferências (frequentemente unilaterais). O diálogo escrito em ambientes virtuais caracteriza-se, portanto, como mais formal e pode ser abundante se não encontrar barreiras de outra natureza (Moore, 2007).

As interações que ocorrem nos ambientes virtuais de aprendizagem influenciam de modo significativo o processo de aprendizagem vivenciado pelo aluno. Da mesma forma, os estados emocionais dos indivíduos interferem em sua capacidade de aprender. Emoções negativas tais como ansiedade, raiva, depressão, tédio ou stress dificultam a assimilação de informações e bloqueiam a aprendizagem (Chuang et al., 2010). As emoções estão intimamente relacionadas com processos de atenção, memorização, criatividade, tomada de decisão e aprendizagem (Picard et al., 2004). Assim, a manifestação da emoção e do conflito pelos estudantes, que pode ser percebida nas interações por ambientes virtuais de aprendizagem, pode indicar a existência de fatores facilitadores ou obstáculos no processo de aprendizagem vivenciado pelo aluno.

\section{CONTEXTO DA PESQUISA}

O objeto de pesquisa deste estudo são as interações realizadas pelos alunos em um curso de graduação brasileiro, que se dá no contexto do Campus Virtual da Universidade do Sul de Santa Catarina - UNISUL. A instituição desenvolve sua própria metodologia e demais recursos para implementar programas de ensino a 
distância. As ações pedagógicas desenvolvidas se baseiam em recursos didáticos, sistema tutorial, suporte tecnológico e avaliação da aprendizagem. Estes recursos e métodos, combinados entre si, apóiam uma metodologia de estudos a distância na qual o aluno interage com os recursos didáticos, com o professor e com os colegas em atividades individuais e colaborativas por meio de um AVA. Os recursos didáticos adotados são compostos principalmente por manuais, livros didáticos, guias de elaboração de projetos e recursos multimídia on line. Além da disponibilidade de recursos síncronos (chats e videoconferências) a maior ênfase das comunicações se dá por ferramentas de comunicação assíncrona como fóruns, tira-dúvidas, murais, exposições, etc. Para cada disciplina do curso há materiais especificamente elaborados, sendo o livro didático da disciplina o principal guia de estudo, complementado pelos materiais e atividades disponibilizadas pelo AVA. O sistema tutorial corresponde à sistemática de atendimento e mediação pedagógica, onde se destacam a atuação do professor, dos monitores e do coordenador do curso. O suporte tecnológico está baseado em um AVA na Internet, que possibilita a comunicação entre os agentes do sistema tutorial para tirar dúvidas, participar de debates, buscar novos materiais e encaminhar atividades e avaliações.

Para o desenvolvimento desta pesquisa coletamos dados em duas ferramentas do AVA: as ferramentas Professor e Turma. A ferramenta Professor é um recurso assíncrono onde o aluno interage diretamente com o professor por livre iniciativa, para registrar comentários, dúvidas ou qualquer outro apontamento que julgue pertinente. Nela o professor responde as dúvidas ou complementa os comentários dos alunos. Esse diálogo é visível para toda a turma e pode ser livremente acessado por qualquer participante. A ferramenta Turma possibilita ao aluno comunicarse com seus colegas por correio eletrônico e o AVA armazena cópia de todas as comunicações nele iniciadas. Essas duas ferramentas estão disponíveis em todas as disciplinas cursadas pelo aluno e se constituem no principal canal de comunicação onde o aluno pode iniciar algum diálogo espontaneamente.

Quanto ao perfil dos alunos do curso em análise, em 2010 ele acolheu 86\% de participantes do sexo masculino e com significativa parcela de alunos concentrados na faixa etária de 25 a 39 anos (65,8\%). Apenas 10\% dos alunos têm idade inferior a 25 anos, 56\% são casados e 75\% já atuam ou atuaram profissionalmente na área de conhecimento do curso (informática). Esses dados revelam um público maduro e com uma carreira profissional já em andamento. 


\section{PROCEDIMENTOS METODOLÓGICOS}

Nesta pesquisa analisamos os diálogos desenvolvidos no AVA pela perspectiva interpretativista com a intenção de compreender em profundidade o significado das interações no processo de ensino e aprendizagem. Os diálogos entre alunos e professor foram extraídos do AVA e gerados em arquivos auxiliares. A partir destes, usamos a análise de conteúdo para categorizar os dados textuais e agrupá-los em categorias conceituais. Segundo Julien (2008), esse método analítico é uma forma de reduzir dados e buscar seus significados por meio de uma leitura acurada do texto, que deve ser interpretado de acordo com seu contexto.

Os diálogos coletados incluíram diferentes disciplinas, de fases iniciais e finais do curso, de modo a abarcar alunos em diferentes etapas de sua formação e em disciplinas que envolvem conteúdos variados. A tabela 1 apresenta uma visão geral dos dados coletados.

\begin{tabular}{|l|c|c|c|}
\hline \multicolumn{1}{|c|}{ Disciplina } & $\begin{array}{c}\text { Fase } \\
\text { do } \\
\text { curso }\end{array}$ & $\begin{array}{c}\text { Quantidade de } \\
\text { comentários enviados } \\
\text { pelos alunos ao } \\
\text { professor }\end{array}$ & $\begin{array}{c}\text { Quantidade de } \\
\text { mensagens enviadas } \\
\text { pelos alunos ao } \\
\text { colegas }\end{array}$ \\
\hline $\begin{array}{l}\text { Fundamentos } \\
\text { para Sistemas de } \\
\text { Informação }\end{array}$ & 1 & 151 & 2 \\
\hline $\begin{array}{l}\text { Organização de } \\
\text { Computadores }\end{array}$ & 1 & 175 & 4 \\
\hline $\begin{array}{l}\text { Prática Profissional } \\
\text { em TI }\end{array}$ & 1 & 141 & 7 \\
\hline Estudo de Caso & 5 & 390 & 1 \\
\hline Gerência de Projetos & 5 & 149 & 10 \\
\hline Gestão Financeira I & 5 & 351 & $\mathbf{2 5}$ \\
\hline Total geral & & $\mathbf{1 . 3 5 7}$ & 1 \\
\hline
\end{tabular}

Tabela 1. Visão geral dos dados coletados no AVA

As manifestações de afeto e conflito explicitadas pelos alunos em suas comunicações pelo AVA são descritas e analisadas a seguir.

\section{ANÁLISE DAS INTERAÇõES NO AVA}

A primeira e mais evidente constatação da observação da tabela 1 é que as interações pelo AVA ocorrem muito mais entre alunos e professores do que dos 
alunos entre si. Esta observação pode indicar que o AVA é um espaço que atende mais as necessidades formais, que envolvem as funções didáticas da interação alunoprofessor. Na análise qualitativa dos diálogos há indicativos de que as interações entre alunos se dão por outros meios ou ambientes mais informais fora do AVA como, por exemplo, as redes sociais. $\mathrm{Na}$ análise detalhada das comunicações dos alunos deparamo-nos com diversas motivações e interesses para interagir no ambiente virtual. Neste artigo destacamos aquelas onde se manifestam o afeto e o conflito.

\section{Visão geral das interações dos alunos pelo AVA}

Ao ingressar no curso, a maioria dos alunos desconhece o funcionamento da dinâmica da modalidade de ensino a distância. Por isso, nas turmas de alunos calouros aparecem diversos tipos de dúvida quanto ao funcionamento das atividades. Há dúvidas freqüentes também quanto à operação das ferramentas do AVA, a metodologia de estudos, sobretudo no que se refere à remessa de avaliações, aos compromissos e cronogramas, à entrega de materiais impressos e aos encontros presenciais. Observamos que as dúvidas operacionais, apesar de relativamente simples, são motivo de ansiedade para o aluno ingressante. À medida que são esclarecidas, os alunos manifestam certa tranqüilidade. Isso pode ser observado na fala do aluno:

"Ok professor, fico muito agradecido e agora começo a entender melhor o funcionamento do curso. Vou colocar as minhas respostas no campo exposição, conforme sua orientação e ficarei aguardando seus comentários. Mais uma vez obrigado".

Este padrão de interação é explicado por Saraiva et al. (2006), que afirmam que ao ingressar no estudo a distância o acolhimento, a sensação de fazer parte são elementos decisivos para superar a barreira tecnológica. Para superar os obstáculos precisam ser feitos investimentos visando assessorar as dificuldades individuais e coletivas.

Ao contrário das dúvidas operacionais e inerentes à metodologia de estudo a distância, as dúvidas relacionadas ao conteúdo das disciplinas são as que se repetem com a mesma intensidade ao logo de toda sua trajetória acadêmica. Estas são mais fortemente exploradas pelos alunos mais avançados no curso, que tendem a explorar mais as ferramentas de interação para este propósito. Observamos também que enquanto os alunos inexperientes limitam-se a dizer que não compreenderam determinado conceito, os alunos mais avançados elaboram e detalham suas dúvidas de modo claro e objetivo. Diferenças nos padrões de interação de alunos calouros e 
veteranos foi também observada em estudo quantitativo realizado no mesmo contexto desta pesquisa. Nele, Mülbert e Schuhmacher (2009) apresentaram resultados que indicaram que os alunos, à medida que avançam seus estudos, amadurecem e transformam sua forma de interagir por meio do AVA. À medida que avança, o aluno altera a frequência e a forma de suas interações, que tendem a diminuir quando o aluno desenvolve confiança em sua própria capacidade de aprender com autonomia e aprende a utilizá-las com maior eficiência.

Segundo Milne (2006) a interação social corresponde a uma parte cada vez mais significativa da aprendizagem, pois cada vez mais os estudantes se sentem motivados a aprender na interação com seus pares. Essa característica do estudante pede, então, por práticas pedagógicas baseadas na colaboração. A colaboração observada no ambiente virtual manifesta-se como um fenômeno que ocorre tanto entre os alunos quanto entre aluno e professor. O desejo de colaborar entre os alunos evidencia-se muito claramente entre os iniciantes, que repetidas vezes manifestam seu interesse em estabelecer trocas e parcerias com seus colegas. A fala do aluno, dirigindo-se por email aos seus colegas, representa esse interesse de troca de experiências na área de conhecimento do curso:

"Pode contar comigo, aliás todos que nunca ouviram falar em MAINFRAME, COBOL, CLIPPER, QBASIC, tudo da minha época, estou aqui para somar e aprender".

A colaboração se estende além das atividades de construção de conhecimentos, como é o caso da aluna que avisa seus colegas sobre os prazos de cumprimento de uma atividade:

"Olá colegas, amanhã é o último dia para o envio da AD [avaliação a distância]. Não vão se perder, eu estou apavorada pois é bem mais difícil quanto parece. Boa sorte a todos".

Moore (2007, p. 47) esclarece que a rede de colaboração estabelecida entre alunos afeta o processo de aprendizagem e influencia nos modos de interação. Os alunos entram em uma comunidade de ideias partilhadas na condição de principiantes e, apoiados por um professor (ou outra pessoa competente), assumem progressivamente a responsabilidade por seu próprio aprendizado. Quanto mais colaboram e interagem entre si, menos dependem da interação com o professor.

As iniciativas de interação para colaborar evidenciam-se como de interesse tanto daqueles que tem recursos a compartilhar como daqueles que usufruem das contribuições. Ao criar um clima colaborativo, relacionamentos são estabelecidos de modo que todos dele possam usufruir. 


\section{Manifestações de afetividade positiva}

Além do conteúdo explícito das interações, identificamos que as mensagens carregam em si conteúdos afetivos bem evidentes ${ }^{1}$. Segundo Longhi et al. (2009), cognição e afetividade constituem elementos indissociáveis. Crenças, desejos e intenções exercem influências sobre os processos cognitivos e estes, por sua vez, ativam as dimensões afetivas do sujeito.

Em nosso estudo, observamos que com frequência os alunos buscam manifestar seu afeto de modo explícito. Várias comunicações carregam em si uma linguagem afetuosa e cordial, como a que podemos observar no depoimento do aluno a seguir. Nele, o aluno revela seu misto de satisfação e ansiedade, assim como agradece de modo afetuoso a contribuição do professor:

"Agradeço de coração a avaliação que me foi dada, é um incentivo a mais para não desistir, estou muito ansioso à chegada da AP [avaliação presencial]. Quero que saiba que em toda minha vida de estudo nunca escrevi tanto assim, só cartas de amor [...] estou muito feliz por ter este começo genial".

As manifestações de agradecimento também ocorrem quando o aluno percebe que o professor vai além das suas atividades formais e demonstra preocupação com o sucesso do aluno:

"Escrevo por dois motivos: Primeiro agradecer pelas contribuições acessórias, além do conteúdo específico, os textos extras e sua preocupação com andamento dos estudos, [...] é primordial para nosso desenvolvimento. Segundo, ao enviar minha $\mathrm{AD}$ [avaliação a distância] tive um problema no upload e fiz novo envio, creio que na segunda tentativa tudo tenha corrido bem. Agradeço pela dedicação e atenção".

Outras manifestações de afetividade foram também encontradas em situações em que há um desafio premente. Na fala a seguir a aluna dirige-se aos colegas tentando mobilizar a todos para reagir diante de uma determinação adversa do professor.

"Parece que estamos enfrentando uma situação incomum. [...] Vamos ver o que vai dar. Todos devem reclamar caso achem justo rever os métodos desta disciplina. Fiquem com Deus".

Segundo Saraiva et al. (2006) "numa relação virtual certas características e dimensões implícitas apontam formas de ser e de configurar sentidos, condições essas de grande significado, tais como a necessidade de estabelecimento de contatos, de ampliação de laços de afetividade com ênfase na imagem e voz de professores e 
alunos e a importância do contato face a face, mesmo que distantes em tempo e espaço" (p. 489).

Observamos também que várias manifestações de afeto estão associadas ao desejo por parte dos alunos de fazer parte de uma comunidade. Participar de um grupo é uma forma de estabelecer uma rede de colaborações, porém, seus benefícios podem ir além da colaboração nas tarefas em si. A participação em grupos pode também gerar sentimentos positivos de apoio, de coragem, de reforço para superação dos obstáculos e desafios. Isso se evidencia quando os alunos destacam o desafio que têm a alcançar juntos, como partícipes de um mesmo movimento e com uma necessidade de superação em comum pela frente. A fala das alunas a seguir representa esse fato:

"Olá!!! Estou entrando em contato para desejar-lhe sucesso neste curso!!! Que possamos juntos alcançar os nossos objetivos através deste curso!".

"Olá turma, hoje posso dizer que estou mais tranquila, confesso que ontem quando entrei nas unidades das disciplinas fiquei preocupada, mas hoje estou mais tranquila e confiante. Espero que todos tenham um ótimo estudo e possamos nos ajudar uns aos outros".

Segundo Mattar (2009, p. 116) a interação aluno/aluno gera motivação e atenção enquanto os alunos aguardam o feedback dos colegas e também diminui a sensação de isolamento do estudo a distância. Essa interação também desenvolve o senso crítico e a capacidade de trabalhar em equipe e, muitas vezes, cria a sensação de pertencer a uma comunidade. Nos diálogos observados o desejo de estabelecer redes de colaboração ficou evidente, tanto para colaborar na realização de tarefas em comum quanto para criar laços solidários e de apoio mútuo.

\section{Manifestação de conflito}

Os espaços de interação em programas de educação a distância apresentam também tensões que afetam o desenvolvimento das atividades educacionais. Os interagentes vivenciam incertezas e apreensões que permeiam as atividades educacionais desenvolvidas a distância (Saraiva et al., 2006). Então, assim como se apresentam desejos e necessidades de vivenciar o afeto, também surgem situações de conflito resultantes de divergências de interesses e/ou opinião. Isso foi observado pela emergência de situações como a que expressa a aluna, em mensagem para seus colegas de turma, quando discorda do posicionamento do professor:

"Estou chocada com a correção da minha AP [avaliação presencial]. O professor não leva em consideração o raciocínio utilizado, só o resultado final. E tudo indica que a 
coordenação do curso vai deixar como está. Absurdo frente à mobilização de tantos alunos prejudicados".

Nesta situação o conflito emerge, mas não é abordado diretamente com o agente que está do lado oposto do conflito, neste caso o professor. Em situações como essa, observamos que o aluno inicia diálogo mais ameno com o professor buscando negociação. Isso pode envolver negociação de prazos, regras, critérios de avaliação, interpretação de questões de avaliação ou outra situação em que há interesses divergentes. Essa negociação se baseia, com freqüência, em uma exposição de motivos que, pela ótica do aluno, justificam seu pleito:

"Professor, assim como o colega anterior, tive problemas que inviabilizaram a entrega da $\mathrm{AD}$ [avaliação a distância] no prazo. Eu e mais 7 colegas de trabalho tivemos uma infecção alimentar e fomos parar no hospital [...] Conto com sua compreensão".

Para Saraiva et al. (2006) professor, tutor e monitor em EAD são agentes que assumem, no processo educacional, posições normalmente geradoras de tensão. Em consonância com nossas observações, em situações de conflito verificamos que emergem as iniciativas de negociação. Uma forma frequentemente encontrada para lidar com os conflitos entre alunos e o professor é a busca pela formação de alianças entre os alunos, que buscam agir de modo coordenado entre si para conseguir, em grupo, mais força em seus argumentos. Isso pode ser representado pela fala da aluna, que comunica-se diretamente com seus colegas em busca de uma aliança e uma ação em conjunto:

"Vamos exercer nosso direto de reclamar. Porque não é possivel a maioria da turma não entender a matéria".

Saraiva et al. (2006) orientam que, mesmo sendo virtual, o cenário em que ocorre o processo educativo é um cenário vivo, móvel e vibrante, em que cada elemento interfere no outro. É um cenário que está em permanente tensão, em que seus elementos desacomodam e afetam uns aos outros. As conexões que vão se estabelecendo originam-se de diferentes demandas, que não estavam previstas e necessitam criar saídas. Formam-se linhas de fuga e problematizações que se modificam em função de necessidades dos atores sociais. Neste sentido, nossas observações indicam que a negociação entre aluno e professor é uma das linhas de fuga encontradas para equacionar as situações inesperadas, com as quais se deparam alunos e professores no decorrer da vida acadêmica.

Outra possível linha de fuga é a busca, por parte dos alunos, de formação redes de colaboração que se desenvolvem fora dos espaços formais representados pelo 
ambiente virtual da instituição de ensino, onde não ocorre a supervisão do professor. Encontramos, nas comunicações entre alunos, diversos convites para interagir em fóruns, chats ou redes sociais fora do AVA. Isto pode ser observado nas falas a seguir:

"Fiz um chat no msn para que possamos interagir melhor, debatendo assuntos sobre as disciplinas e etc, o endereço do chat é [...]".

"Olá colegas. Quem tiver twitter e quiser podemos nos seguir".

A saída para a interação em ambientes onde não há supervisão dos agentes do sistema formal de ensino revela o desejo que o grupo tem de privacidade e informalidade. Dessa forma, o aluno sente-se mais livre para conversar com seus pares sobre suas dificuldades e conflitos, bem como encontra espaço para uma eventual articulação do grupo para se preparar para uma negociação com os agentes do sistema formal de ensino. Essa necessidade de liberdade de interação é relatada como uma tendência por Downes (2010), que explica que a aprendizagem e a interação da "geração net" já se desenvolveu a partir do paradigma das redes digitais, onde a rede de relacionamentos informais é democrática, seus membros são autônomos, com liberdade para negociar e trocar informações. Assim sendo, a busca dos alunos por formar redes paralelas para interagir fora do ambiente virtual institucional promove melhores condições para lidar com o conflito e a negociação.

Outro aspecto de destaque é que o padrão de interatividade dos alunos alterase à medida que os alunos avançam e aprimoram sua experiência no AVA. Alunos novatos buscam mais pela afiliação e integração grupal, e estão mais preocupados em demonstrar seu afeto positivo. Mas quando os objetivos de afiliação ao grupo já estão mais consolidados, no caso dos alunos mais experientes, a manifestação do conflito se torna mais evidente. Observamos que os conflitos são mais freqüentes com os alunos que já tem seus vínculos com colegas mais fortalecidos, que têm maior conhecimento da metodologia de ensino on line e maior experiência nas interações virtuais por meio do AVA institucional. Portanto, parece ser preciso ter raízes e vínculos significativos para dar sustentação à manifestação do conflito.

A dinâmica da convivência entre os indivíduos pode ser explicada pelos movimentos típicos das relações interpessoais em grupos. A integração grupal, segundo Schutz (1978), inicia-se pelo esforço de inclusão no grupo, quando os membros da turma se esforçam para ser conhecidos e aceitos. Por isso, no início da integração grupal os indivíduos dedicam esforços para mostrarem-se significativos e com algum mérito que justifique sua aceitação no grupo. A fase de inclusão é um momento em que muitos tentam se mostrar positivamente para garantir aceitação. 
Nas fases seguintes da integração grupal, que correspondem às fases de controle e de afeto, a manifestação dos sentimentos, sejam eles positivos ou negativos, se dá com maior intensidade. À medida que a convivência grupal avança o indivíduo se sente fortalecido para exercer controle e autoridade sobre os outros e para manifestar seus reais sentimentos mais abertamente. Esses mecanismos existentes na interação foram originalmente observados em grupos presenciais, mas pela análise dos diálogos estudados parecem manifestar-se também em ambientes de convivência on line.

\section{CONSIDERAÇÕES FINAIS}

A partir da análise do conteúdo das comunicações realizadas em um AVA, buscamos identificar a manifestação do afeto e do conflito na educação on line. Identificamos que mesmo nas interações a distância, realizadas por meio da palavra escrita, é possível reconhecer emoções e sentimentos. As interações habitualmente esperadas em ambientes virtuais no ensino superior são aquelas que contribuem objetivamente para a realização das tarefas acadêmicas. Contudo, na convivência que se estabelece por meio de AVAs verificam-se manifestações de afeto e conflito que seguramente interferem nos resultado final do processo de aprendizagem. Reconhecer tal dinâmica pode ser de importância significativa para a melhoria da prática docente em sistemas de educação on line, bem como para a construção de espaços de aprendizagem que potencializem a manifestação do afeto e a superação do conflito. Assim, a percepção, por parte de professores e demais agentes do sistema tutorial, do valor das interrelações estabelecidas por AVAs pode contribuir para enaltecer a importância de interagir com qualidade e com isso contribuir para a melhoria do processo de aprendizagem vivenciado pelos alunos. Além disso, os resultados desta pesquisa indicam que a qualidade das interações pode ser também um critério de avaliação e monitoramento pelos gestores do sistema de aprendizagem.

\section{NOTA}

1. Consideramos aqui os contatos de afeto em sua forma positiva. Não consideramos como afeto as emoções ou estados de ânimo negativos ou conflitivos. O conflito é abordado em separado.

\section{REFERENCIAS BIBLIOGRÁFICAS}

Chuang, H. C.; Wang, C. Y.; Chen, G. D.; Liu, C. C.; Liu, B. J. (2010). Design and Evaluation of an Affective Interface of the E-learning Systems. 1oth IEEE International Conference on Advanced Learning Technologies. Anais.
(202-203). IEEE Computer Society. [en línea] Disponível em: http://ieeexplore.ieee.org/lpdocs/epic03/wrapper. htm?arnumber $=5571251$ [consulta 2013, 5 de mayo]. 
Downes, S. (2010). Learning Networks and Connective Knowledge. In Yang, H.; Yuen, S. Collective Intelligence and ELearning 2.o. New York: Information Science Reference.

García Aretio, L. (1994). Educación a distancia. Bases conceptuales. In García Aretio, L. Educación a distancia hoy. Madrid: Universidad de Educación a Distância, (11- 57).

Julien, H. (2008). Content analisys. In Given, L. M. (ed.). The SAGE encyclopedia of qualitative research methods,1 y 2 . Thousand Oaks, CA: Sage, (120-121).

Longhi, M. T; Behar, P. A.; Bercht, M. (2009). A busca pela dimensão afetiva em ambientes virtuais de aprendizagem. In Behar, P. A. (org.). Modelos pedagógicos em educação a distância. Porto Alegre: Artmed, (204-231).

Mattar, J. (2009). Interatividade e aprendizagem. In Litto, F. M.; Formiga, M. (orgs.). Educação a distância: o estado da arte. São Paulo: Pearson, (112-120).

Milne, A. J. (2006). Designing Blended Learning Space to the Student. In: Oblinger, D. G (ed). Learning spaces. EDUCAUSE. Cap. 12, (142-157).

Moore, M.; Kearsley, G. (2007). Educação a distância. São Paulo: Thomson.
Mülbert, A. L.; Schuhmacher, V. R. (2009). Interaction Maturity of the Distance Learning Students. ICBL2009. Anais, 1. Florianópolis.

Neder, M. L. C. (1999). A Formação do Professor a Distância: diversidade como base conceitual. Cuiabá: Universidade Federal Mato Grosso.

Oblinger, D. G. (2006). Space as a Change Agent. In: Oblinger, D. G (ed). Learning spaces. EDUCAUSE. cap. 1, (12-16).

Picard, R. W.; Papert, S.; Bender, W. et al. (2004). Affective Learning - A Manifesto. BT Technology Journal, 22 (4), (253-269). [en línea]. Disponível em: http://www.springerlink. com/openurl.asp?id=doi:10.1023/ B:BTTJ.0000047603.37042.33. [consulta 2013, 5 de mayo].

Saraiva, L. M.; Pernigotti, J.; Barcia, R. M.; Lapolli, E. M. (2006). Tensões que afetam os espaços de educação a distância. Revista Psicologia em Estudo, 11(3), Maringá, (483-491). [en línea] Disponível em: http://www.scielo.br/pdf/pe/ v11n3/v11n3a03.pdf [consulta 2013, 5 de mayo].

Schutz, W. (1978). Psicoterapia pelo encontro. Rio de Janeiro: Atlas.

\section{PERFIL ACADÊMICO E PROFISSIONAL DOS AUTORAS}

Ana Luisa Mülbert. Aluna de doutorado do Programa de Pós-graduação em Engenharia e Gestão do Conhecimento - EGC na área de Mídia do Conhecimento da Universidade Federal de Santa Catarina (UFSC).

Email: amulbert@gmail.com

Ariane Girondi. Aluna de mestrado do Programa de Pós-graduação em Engenharia e Gestão do Conhecimento - EGC na área de Mídia do Conhecimento da Universidade Federal de Santa Catarina (UFSC).

Email: agirondi@gmail.com 
Alice T. Cybis Pereira. Professora Dra. do Programa de Pós-graduação em Engenharia e Gestão do Conhecimento - EGC na área de Mídia do Conhecimento da Universidade Federal de Santa Catarina (UFSC).

Email: acybis@gmail.com

Marina Keiko Nakayama. Professora Dra. do Programa de Pós-graduação em Engenharia e Gestão do Conhecimento - EGC na área de Mídia do Conhecimento da Universidade Federal de Santa Catarina (UFSC).

Email: marina@egc.ufsc.br

\section{DIRECCIÓN DE LAS AUTORAS}

UNIVERSIDADE FEDERAL DE SANTA CATARINA Centro de Comunicação e Expressão

Departamento de Expressão Gráfica

Campus Trindade - caixa postal 476

Cep. 88040270

Florianópolis, Santa Catarina (Brasil)

Fechas de recepción del artículo: 12/01/13

Fecha de aceptación del artículo: 24/05/13

\section{Como citar este artículo:}

Mülbert, A. L.; Girondi, A.; Cybis Pereira, A. T.; Keiko Nakayama, M. (2013). Afecto e conflicto en las interacciones em ambientes virtuales de aprendizaje. RIED. Revista Iberoamericana de Educación a Distancia, volumen 16, $\mathrm{n}^{\circ}$ 2, pp. 59-72. 